\title{
Pretreatment of sweet sorghum straw and its enzymatic digestion: insight into the structural changes and visualization of hydrolysis process
}

Miaoyin Dong ${ }^{1,3}$, Shuyang Wang ${ }^{1,2,3^{*}}$, Fuqiang $\mathrm{Xu}^{1,3}$, Junkai Wang ${ }^{4}$, Ning Yang ${ }^{5^{*}}$, Qiaoqiao Li ${ }^{1,3}$, Jihong Chen ${ }^{1,3}$ and Wenjian $\mathrm{Li}^{1,3}$

\begin{abstract}
Background: The efficient utilization of lignocellulosic biomass for biofuel production has received increasing attention. Previous studies have investigated the pretreatment process of biomass, but the detailed enzymatic hydrolysis process of pretreated biomass remains largely unclear. Thus, this study investigated the pretreatment efficiency of dilute alkali, acid, hydrogen peroxide and its ultimate effects on enzymatic hydrolysis. Furthermore, to better understand the enzymatic digestion process of alkali-pretreated sweet sorghum straw (SSS), multimodal microscopy techniques were used to visualize the enzymatic hydrolysis process.
\end{abstract}

Result: After pretreatment with alkali, an enzymatic hydrolysis efficiency of $86.44 \%$ was obtained, which increased by $99.54 \%$ compared to the untreated straw (43.23\%). The FTIR, XRD and SEM characterization revealed a sequence of microstructural changes occurring in plant cell walls after pretreatment, including the destruction of lignin-polysaccharide interactions, the increase of porosity and crystallinity, and reduction of recalcitrance. During the course of hydrolysis, the cellulase dissolved the cell walls in the same manner and the digestion firstly occurred from the middle of cell walls and then toward the cell wall corners. The CLSM coupled with fluorescent labeling demonstrated that the sclerenchyma cells and vascular bundles in natural SSS were highly lignified, which caused the nonproductive bindings of cellulase on lignin. However, the efficient delignification significantly increased the accessibility and digestibility of cellulase to biomass, thereby improving the saccharification efficiency.

Conclusion: This work will be helpful in investigating the biomass pretreatment and its structural characterization. In addition, the visualization results of the enzymatic hydrolysis process of pretreated lignocellulose could be used for guidance to explore the lignocellulosic biomass processing and large-scale biofuel production.

Keywords: Sweet sorghum straw, Pretreatment, Structural characterization, Enzymatic hydrolysis process, Visualization

\section{Background}

The ever-increasing demand for energy and environmental concern is forcing the exploration of sustainable energy from the renewable substrates, aiming at reducing our dependence on fossil fuels [1,2]. Lignocellulose

\footnotetext{
*Correspondence: wangsy@impcas.ac.cn; xbsd-yn@163.com ${ }^{1}$ Institute of Modern Physics, Chinese Academy of Sciences, 509 Nanchang Rd., Lanzhou 730000, Gansu, People's Republic of China ${ }^{5}$ College of Life Sciences, Northwest Normal University, Anning Rd., Lanzhou 730000, Gansu, People's Republic of China

Full list of author information is available at the end of the article
}

is one of the most abundant organic materials on Earth, including energy crops, agricultural and forestry residues, and its conversion to a variety of valuable products such as liquid fuels and other carbon-based materials has attracted considerable concern [3, 4]. Sweet sorghum (Sorghum bicolor), a energy corp in China that can be cultivated in harsh growth conditions, is a promising candidate for generating abundant plant biomass [5].

The native biomass has a complex hierarchical and heterogeneous structure, which is composed of cellulose, hemicellulose, lignin, and other polysaccharides 
[6]. Unfortunately, the natural recalcitrance of lignocelluloses, particularly the non-polysaccharide aromatic polymer lignin, posed significant resistance to enzymatic and microbial deconstruction in biomass processing [7]. Therefore, the exploration of efficient and selective pretreatment systems and hydrolysis processes was necessary to achieve the efficient utilization of lignocellulose substrates. To improve the saccharification efficiency of natural lignocelluloses, different pretreatment technologies including chemical, physical and biological approaches have been initiated prior to enzymatic hydrolysis [8]. The main goals of pretreatment were to reduce biomass recalcitrance via minimizing the impact of lignin-hemicellulose matrix and producing digestible cellulose residues. In our previous study, the effect of heavy-ion beam irradiation pretreatment on enzymatic hydrolysis of sweet sorghum straw was investigated. We found that the heavy-ion beam irradiation caused the transformation of polymorphs $\left(I_{\alpha} \rightarrow I_{\beta}\right)$ of cellulose $I$, thereby increasing the enzymatic digestibility of the biomass [9]. However, this irradiation pretreatment requires a sophisticated accelerator device, which also means high cost and limits its industrial application. In addition, biological pretreatment is a relatively time-consuming process, and its hydrolysis rate was lower as compared to other technologies $[10,11]$. However, chemical pretreatment, such as using dilute alkali, acid and oxidant, is an economical and efficient pretreatment process that uses relatively low temperatures and pressures [10, 12].

Although many of the pretreatment processes of biomass have been widely studied, the detailed enzymatic hydrolysis process of pretreated biomass remains largely unclear. The visualization techniques and cellulase protein labeling approaches were implemented to represent the detailed information of accessibility and digestibility of cellulase to pretreated biomass $[13,14]$. He et al. [15] investigated in situ visualization in lignocellulosic hydrolysis via making a fusion enzyme with green fluorescence protein (GFP). They found that the absorption ability of enzyme protein could not consistently reflect the digestibility of lignocellulose. The possible reason is that the binding and hydrolysis efficiency of the fusion enzyme might be affected by the inserted GFP in that the size of GFP is not negligible [16]. Nevertheless, a deeper understanding of the enzymatic hydrolysis process of pretreated biomass is necessary to enhance the lignocellulosic biomass processing [17].

In this study, we investigated the various pretreatment efficiencies $\left(\mathrm{NaOH}, \mathrm{H}_{2} \mathrm{SO}_{4}, \mathrm{H}_{2} \mathrm{O}_{2}\right)$ and its ultimate effects on enzymatic hydrolysis. Then, FTIR, XRD and SEM were used to characterize the effects of pretreatment and enzymatic hydrolysis on the microstructure of the biomass. Furthermore, to better understand the enzymatic hydrolysis process of alkali-pretreated biomass, the real-time imaging analysis of the hydrolysis process was carried out. In addition, the CLSM coupled with fluorescent-labeling techniques was used to visualize the spatial changes in the accessibility and digestibility of cellulase to the pretreated biomass during hydrolysis.

\section{Materials and methods \\ Sweet sorghum straw}

The sweet sorghum straw was collected from the experimental field of the Institute of Modern Physics, Gansu (latitude $37.93^{\circ} \mathrm{N}$, longitude $102.63^{\circ} \mathrm{E}$ ), China. After drying at $60^{\circ} \mathrm{C}$ in an oven for $48 \mathrm{~h}$, the straw was ground in a milling machine and passed through size 40 mesh sieves. To visualize the enzymatic hydrolysis process, the transverse slices ( $20 \mu \mathrm{m}$ and $10 \mu \mathrm{m}$ in thickness) of sweet sorghum stem (fifth internode) were prepared using Leica microtome (RM2265, China). Then, the transverse sections were dewaxed in xylene and rehydrated with graded ethanol as described in Kim et al. [18] and dried at $60{ }^{\circ} \mathrm{C}$ to a constant weight.

\section{Preparation of cellulase enzyme}

The cellulase enzymes ( $T$. longibrachiatum LC-M4) were provided by the Institute of Modern Physics and its filter paper activity was $66.7 \mathrm{FPU} / \mathrm{g}$. For the cellulase labeling, $1 \mathrm{mg}$ of fluorescein isothiocyanate (FITC) was dissolved in $1 \mathrm{~mL}$ anhydrous dimethyl sulfoxide (DMSO), then the cellulase $(20 \mathrm{mg})$ was added to the FITC solution and the labeling reaction was performed in the dark at $4{ }^{\circ} \mathrm{C}$ for $8 \mathrm{~h}$. After incubation, the free dyes were removed by the centrifuging process using $10 \mathrm{kDa}$ centrifugal membrane concentrator (Millipore, China).

\section{Pretreatment of sweet sorghum straw}

$\mathrm{H}_{2} \mathrm{SO}_{4}$ at a concentration of $2 \%(\mathrm{v} / \mathrm{v})$ was used to pretreat $5 \mathrm{~g}$ ground SSS samples at a solid loading of $10 \%(\mathrm{w} / \mathrm{v})$ in $250 \mathrm{~mL}$ Erlenmeyer flasks. Pretreatment was performed in an autoclave at $121^{\circ} \mathrm{C}$ for $1 \mathrm{~h} .2 \% \mathrm{NaOH}(\mathrm{w} / \mathrm{v})$ and $10 \%$ hydrogen peroxide $(\mathrm{v} / \mathrm{v})$ pretreatment was carried out at $10 \%(\mathrm{w} / \mathrm{v})$ biomass loading in $250 \mathrm{~mL}$ Erlenmeyer flasks and at $100{ }^{\circ} \mathrm{C}$ for $1 \mathrm{~h}$, respectively. The transverse section slices were pretreated with $2 \% \mathrm{NaOH}(\mathrm{w} / \mathrm{v})$ in a glass Petri dish $(90 \mathrm{~mm})$ at the same conditions as described above. Then the pretreated samples were washed with distilled water until the $\mathrm{pH}$ was neutral and dried at $60{ }^{\circ} \mathrm{C}$ to a constant weight.

\section{Enzymatic hydrolysis of sweet sorghum straw}

The enzymatic hydrolysis was performed as described in our previous study [19]. Briefly, the SSS with or without pretreatment, cellulase (9 FPU/g substrate) and 
citric acid buffer solution ( $50 \mathrm{mM}, \mathrm{pH} 4.8)$ were added to $150 \mathrm{~mL}$ Erlenmeyer flasks at a substrate mass concentration of $1 \mathrm{~g} / 20 \mathrm{~mL}$. Then, the hydrolysis reaction was carried out with a stirring rate of $150 \mathrm{rpm}$ at $50{ }^{\circ} \mathrm{C}$ for $72 \mathrm{~h}$. After enzymatic hydrolysis, $1 \mathrm{~mL}$ of the sample was centrifuged at $8000 \mathrm{rpm}$ for $10 \mathrm{~min}$ and the total glucose contents were measured by the HPLC method [20]. The enzymatic hydrolysis efficiency was calculated as described in our previous study [19]. Based on the delignification capability and hydrolysis efficiency for SSS, the best pretreatment method was used for further enzymatic hydrolysis process study.

\section{Analytical methods}

The contents of cellulose, hemicellulose and lignin in the samples before and after pretreatment were calculated by following the National Renewable Energy Laboratory (NREL) method as described in Sluiter et al. [21]. The surface morphology of pretreated and enzyme-hydrolyzed samples was imaged using NanoSEM 490 SEM (FEI.Co, USA) with an accelerating voltage of $15 \mathrm{kV}$ at magnifications of 1000 [22]. The crystalline phases of pretreated and hydrolyzed straws were characterized by X-ray diffractogram (XRD, Bruker D5005, Karlsruhe, Germany). The samples were scanned from $10^{\circ}$ to $40^{\circ}$ with a step size of $0.05^{\circ}$ and the crystallinity index (CrI) was determined by following "Segal" method (Eq. 1) as described in Segal et al. [23].

$$
\operatorname{CrI}(\%)=\left(I_{002}-I_{\mathrm{am}}\right) / I_{002} \times 100 \%,
$$

where $I_{002}$ is the highest peak intensity at $2 \theta=22^{\circ}$ and $I_{\text {am }}$ is the intensity of amorphous portion at $2 \theta=18^{\circ}$.

In addition, the FTIR spectrometer (Bruker Tensor 27, Germany) was used for revealing the changes of the functional groups in pretreated and hydrolyzed straws. Samples were prepared by grinding with $\mathrm{KBr}$ at a ratio of $1: 100(\mathrm{w} / \mathrm{w})$ and pressing into pellets. The spectra were recorded within a range of $400-4000 \mathrm{~cm}^{-1}$ with a resolution of $4 \mathrm{~cm}^{-1}$ and 32 scans per sample [24].

\section{Real-time imaging analysis on the enzymatic hydrolysis process of alkali-pretreated SSS}

The enzymatic hydrolysis of alkali-pretreated transverse sections was carried out in a glass Petri dish $(35 \mathrm{~mm})$ at room temperature. Enzyme loading was estimated roughly as $9 \mathrm{FPU} / \mathrm{g}$ substrate based on the average weight of stem transverse sections. For real-time imaging of the enzymatic hydrolysis process, the bright-field light microscopy (Olympus BX53, Japan) was used and individual images were taken with time intervals of $60 \mathrm{~min}$ in the same area. In addition, the digestion movies were recorded at minute time intervals in the same area.

\section{Visualization of the spatial accessibility and digestibility of cellulase to alkali-pretreated SSS}

For cell wall binding, $100 \mu \mathrm{L}$ labeled enzymes were added to the pretreated stem transverse section and incubated on slides at room temperature and rinsed three times with PBS buffer ( $\mathrm{pH} 7.4,10$ min per time). Then the confocal laser scanning microscopy (CLSM, LSM 700, ZEISS, Germany) was used for observing the accessibility and digestibility of labeled cellulase on the surface of stem transverse sections. The labeled cellulase was excited by $488 \mathrm{~nm}$ laser and detected by a $515 / 30 \mathrm{~nm}$ emission filter, and the autofluorescence of straw was excited by $543 \mathrm{~nm}$ laser and detected by $605 / 75 \mathrm{~nm}$ emission filter [14]. Multi-track image acquisition techniques were used to minimize cross talk of fluorescence emission. All CLSM images were recorded at the same conditions and analyzed using Image J (http://rsb.info.nih. gov/ij/) by the following procedure: "Open" the original CLSM images with Image $J \rightarrow$ "Analyze" $\rightarrow$ "Measure", and then record the intensities of dye-labeled fluorescence and autofluorescence, respectively. The relative intensities of dye-labeled fluorescence and autofluorescence were expressed as percentages compared with the intensities of fluorescence in untreated samples that were designated as $100 \%$, respectively. For quantitative analysis of cellulase binding, the average fluorescence intensities were calculated based on a total of ten images from at least five independently labeled tissue sections.

\section{Statistical analysis}

The statistical analyses were performed using the Origin 9.0 and SPSS 20.0 (SPSS V20.0). All presented values are the means of at least three replicates. Tukey's test was employed for different sample means and significance was declared at $P<0.05$.

\section{Results and discussion \\ Analysis of chemical compositions and enzymatic hydrolysis efficiency}

The contents of cellulose, hemicellulose and lignin in biomass are crucial factor for bioconversion. Generally, these compositions vary in amounts because of the difference in growth conditions and species [25]. In this study, the untreated SSS contained $37.74 \%$ cellulose, $28.07 \%$ hemicelluloses and $21.48 \%$ lignin (Table 1). The hemicellulose and lignin contents of SSS were much higher than other agro-residues, such as rice straw and wheat straw $[26,27]$. These results suggested that an appropriate pretreatment was necessary to produce fermentable sugars using the SSS as feedstock.

The contents of cellulose were significantly increased after pretreatment and the highest contents of $71.36 \%$ 
were obtained in $2 \% \mathrm{NaOH}$-pretreated SSS (Table 1). This increase of cellulose contents indicated that a large number of cellulose located in cell walls were released from the hemicellulose-lignin matrix after pretreatment [27]. The lignin contents in $2 \% \mathrm{NaOH}$-treated SSS were significantly decreased to $6.29 \%$, which were suitable for further enzymatic hydrolysis. $2 \% \mathrm{H}_{2} \mathrm{SO}_{4}$ pretreatment resulted in efficient removal of hemicellulose components in SSS, while $10 \% \mathrm{H}_{2} \mathrm{O}_{2}$ is the least effective in delignification. According to Moxley et al. [28], the hemicellulose is generally diffused into the interfibrillar space through the fiber pores and cross-linked the cellulose microfibrils and lignin, which reduced the accessibility of the cellulose to cellulases. They demonstrated that the dilute acid pretreatment significantly improved the enzyme accessibility through xylan solubilization and lignin degradation.

As can be seen from Table 1, the enzymatic hydrolysis efficiency was significantly improved after pretreatment and $2 \% \mathrm{NaOH}$-pretreated sample exhibited the highest efficiency (86.44\%), followed by $2 \% \mathrm{H}_{2} \mathrm{SO}_{4}(75.07 \%)$ and then $10 \% \mathrm{H}_{2} \mathrm{O}_{2}(66.6 \%)$ pretreatment. Ioelovich et al. [29], who applied both $\mathrm{NaOH}$ and dilute $\mathrm{H}_{2} \mathrm{SO}_{4}$ to four materials (poplar, switchgrass, corncobs and rice straw), reported alkali pretreatment to be more efficient in terms of delignification, sugar yields, and biomass utilization rate. In this study, the increase of hydrolysis efficiency in $\mathrm{H}_{2} \mathrm{O}_{2}$ pretreatment might be due to the oxidative delignification that can increase lignin solubilization and cellulose availability [30,31]. It was noted that the hydrolysis efficiency of SSS was negatively related to the contents of lignin or hemicellulose, which affects the enzymatic hydrolysis by binding to cellulose, thereby decreasing the possibility of cellulose contacting cellulase [32].

\section{Effect of pretreatment and enzymatic hydrolysis on the structures of SSS \\ Fourier transform infrared (FTIR) spectroscopy analysis}

Figure 1 shows the changes in the chemical structure of SSS after pretreatment and enzymatic hydrolysis. The spectral band at $3403 \mathrm{~cm}^{-1}$ was attributed to the hydroxyl group $(-\mathrm{OH})$ stretching vibrations in hemicellulose and hydrogen-bonded water molecules absorbed by the polymers [33, 34]. Thus, the broad band at $3403 \mathrm{~cm}^{-1}$ could not clearly resolve the vital information about the changes in biomass structure during pretreatment and enzymatic hydrolysis due to the overlap of $-\mathrm{OH}$ stretching vibrations from hemicellulose and hydrogenbonded water [35]. The band at $1735 \mathrm{~cm}^{-1}$ represents the characteristic peaks of the hemicellulose-lignin complex. The intensity of $2 \% \mathrm{H}_{2} \mathrm{SO}_{4}$-pretreated SSS was decreased, while it disappeared in $2 \% \mathrm{NaOH}$-pretreated SSS, indicating that the alkaline pretreatment could not only hydrolyze the lignin fraction but also extract some hemicellulose [26]. The peaks at $1510 \mathrm{~cm}^{-1}$ (guaiacyl ring from lignin) almost disappeared in $\mathrm{NaOH}$-pretreated SSS, which indicated the occurrence of extensive delignification. McMillan et al. [36] demonstrated that the saponification reactions between $\mathrm{NaOH}$ and intermolecular ester bonds in lignin were the key factors causing lignocellulosic structure changes after $\mathrm{NaOH}$ pretreatment, which contributes to lignin removal and cellulose release, while this spectral band at $1510 \mathrm{~cm}^{-1}$ could be seen in untreated, $2 \% \mathrm{H}_{2} \mathrm{SO}_{4}$ and $10 \% \mathrm{H}_{2} \mathrm{O}_{2}$-treated $\mathrm{SSB}$, which were there even after enzymatic hydrolysis. These results indicated that the lignin components of SSS cannot be removed by the acid or oxidant pretreatment, and cannot also be digested by cellulase.

The hemicellulose peaks (acetyl groups $\mathrm{C}-\mathrm{O}$ ) were obviously identified at $1250 \mathrm{~cm}^{-1}$ in untreated and $10 \% \mathrm{H}_{2} \mathrm{O}_{2}$-treated SSB, and an increase in intensity of untreated, $2 \% \mathrm{H}_{2} \mathrm{SO}_{4}$ - and $10 \% \mathrm{H}_{2} \mathrm{O}_{2}$-treated SSB was observed after hydrolysis indicated that the acetyl groups in hemicellulose were partially exposed due to cellulose digestion. A previous study reported that the hemicellulose backbone and its side chains in cell walls could inhibit the formation of productive binding between the catalytic domain of cellulases and cellulose, thereby limiting the cellulose accessibility [37]. In addition, the acetyl groups can increase the diameter of cellulose chains, thus slowing the enzymatic hydrolysis rate by increasing the steric hindrance of enzymes [38]. Therefore,

Table 1 Chemical composition and enzymatic hydrolysis efficiency of sweet sorghum straw before and after pretreatment

\begin{tabular}{lllcc}
\hline Samples & \multicolumn{2}{c}{ Chemical composition (\%) } & & $\begin{array}{l}\text { Enzymatic } \\
\text { hydrolysis } \\
\text { efficiency (\%) }\end{array}$ \\
\cline { 2 - 5 } & Cellulose & Hemicellulose & Lignin & $43.23 \pm 0.9$ \\
\hline Untreated [19] & $37.74 \pm 1.61$ & $28.07 \pm 1.12$ & $21.48 \pm 0.63$ & $86.44 \pm 3.42$ \\
$2 \% \mathrm{NaOH}_{119]}$ & $71.36 \pm 3.2$ & $16.15 \pm 0.84$ & $6.29 \pm 0.07$ & $75.07 \pm 1.08$ \\
$10 \% \mathrm{H}_{2} \mathrm{SO}_{4}$ & $57.80 \pm 0.95$ & $11.76 \pm 0.27$ & $17.83 \pm 0.8$ & $66.60 \pm 1.37$ \\
\hline
\end{tabular}

a Based on dry weight of samples 

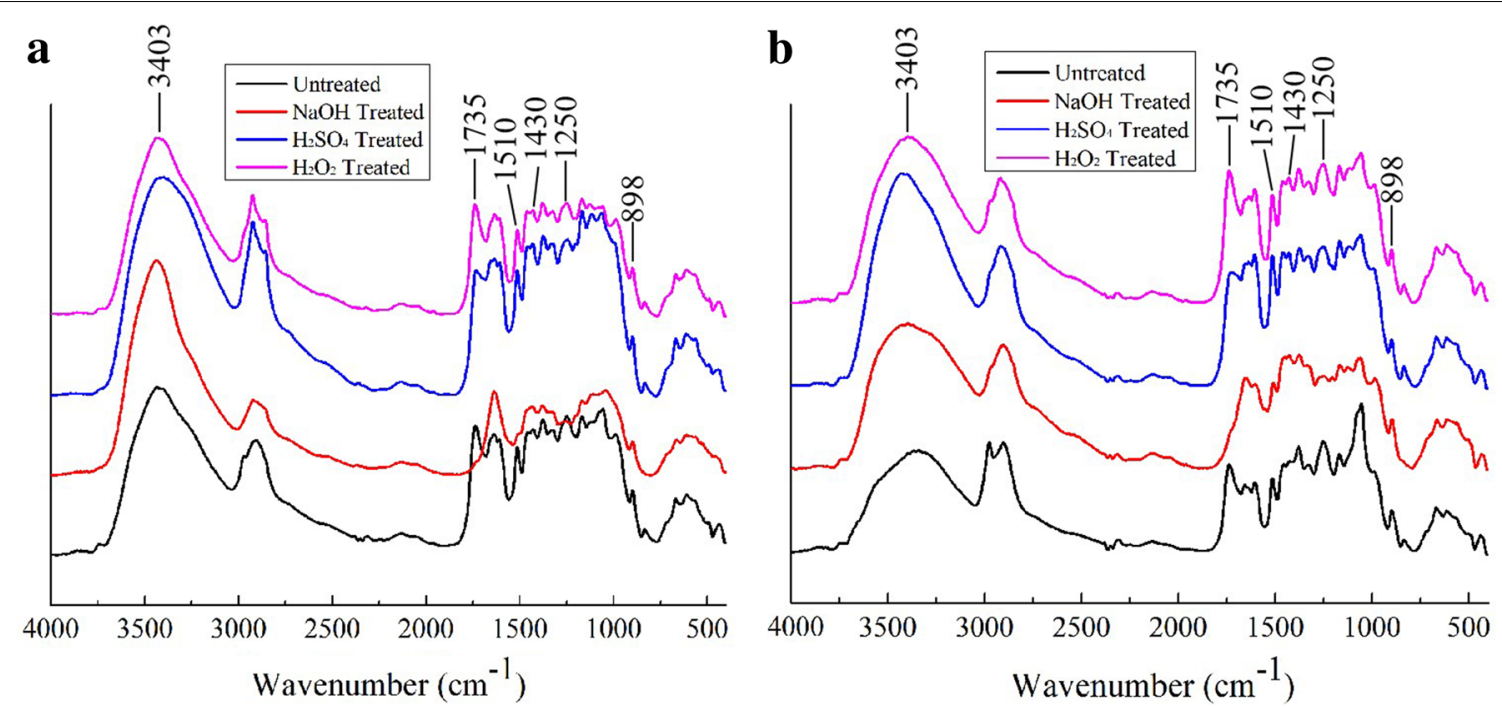

Fig. 1 FTIR spectroscopy of SSS after pretreatment (a) and enzymatic hydrolysis (b)

the hemicellulose was typically thought to impede the enzymatic digestion of cellulose via forming a physical barrier on the cellulose microfibril surface $[39,40]$, but the barrier of hemicellulose seems to be less important compared to the effect of lignin in that the hemicellulose is easy to remove during enzymatic hydrolysis (hemicellulase) or the pretreatment process [41]. The bands at $1430 \mathrm{~cm}^{-1}$ and $898 \mathrm{~cm}^{-1}$ were labeled as cellulose I and the mixture of cellulose II and amorphous cellulose absorption band, respectively [42, 43]. It was reported that the absorption band at $898 \mathrm{~cm}^{-1}$ was attributed to the $\mathrm{C}-\mathrm{O}-\mathrm{C}$ stretching vibrations of $\beta-(1-4)$-glycosidic linkage in cellulose II and amorphous cellulose [44]. Thus, the band at $898 \mathrm{~cm}^{-1}$ was resolved to be that of the mixture of cellulose II and amorphous cellulose. The decrease in intensity at $898 \mathrm{~cm}^{-1}$ and increase in intensity at $1430 \mathrm{~cm}^{-1}$ after pretreatment were mainly caused by the partial removal of lignin and hemicellulose from the biomass matrix, thereby releasing cellulose [44]. A further decrease in intensity at $898 \mathrm{~cm}^{-1}$ could be seen after hydrolysis in all pretreated SSS, because the more amorphous cellulose was hydrolyzed by cellulase compared with the untreated SSS.

\section{$X$-ray diffraction (XRD) analysis}

The crystalline feature, as the structural property of lignocellulose, plays an important role in the enzymatic hydrolysis and bioconversion of the biomass [24]. As shown in Fig. 2, the peaks at $16.3^{\circ}$ and $22.0^{\circ}$ were significantly higher in all pretreated and hydrolyzed SSS (especially in alkali-pretreated and hydrolyzed SSS) than in the untreated sample. The crystallinity index (CrI) was employed to elaborate the crystalline degree of lignocellulose. The $\mathrm{CrI}$ of untreated and $2 \% \mathrm{NaOH}-, 2 \% \mathrm{H}_{2} \mathrm{SO}_{4}$ and $10 \% \mathrm{H}_{2} \mathrm{O}_{2}$-treated SSS were $45.50 \%, 69.30 \%, 66.45 \%$ and $53.06 \%$, respectively (Table 2 ). The increase of $\mathrm{CrI}$ in pretreated SSS was attributed to the removal of hemicellulose and lignin, both of which are amorphous in the native biomass [45]. A previous study reported that the chemical pretreatment could increase the crystallinity of the lignocellulosic biomass due to the removal of hemicellulose or lignin components [45]. Kainthola et al. [46] reported that the fungal pretreatment of rice straw decrystallized the crystalline part of the substrate, thereby decreasing the crystallinity. These differences may be related to the types of biomass, the conditions of pretreatment and actions of cellulase.

Interestingly, the CrI of untreated and pretreated SSS were further increased after enzymatic hydrolysis when compared with the raw and only pretreated SSS (Fig. 2). We observed that the $\mathrm{CrI}$ of $2 \% \mathrm{NaOH}-, 2 \% \mathrm{H}_{2} \mathrm{SO}_{4^{-}}$and $10 \% \mathrm{H}_{2} \mathrm{O}_{2}$-pretreated SSS increased up to $77.47 \%, 71.68 \%$ and $64.95 \%$ from $53.90 \%$ of untreated SSS after enzymatic hydrolysis, respectively (Table 2). Because the CrI measures the relative fraction of crystalline cellulose in the total solid, it is widely impacted by the presence of lignin and hemicellulose, crystalline and amorphous regions in cellulose [37]. Zhang et al. [47] reported that a slower hydrolysis of crystalline cellulose as compared to amorphous cellulose would increase the percentage crystallinity of the hydrolyzed biomass. Therefore, the further increase of CrI in hydrolyzed SSS was attributed to the digestion of amorphous cellulose released from the lignin and hemicellulose matrix after pretreatment. 


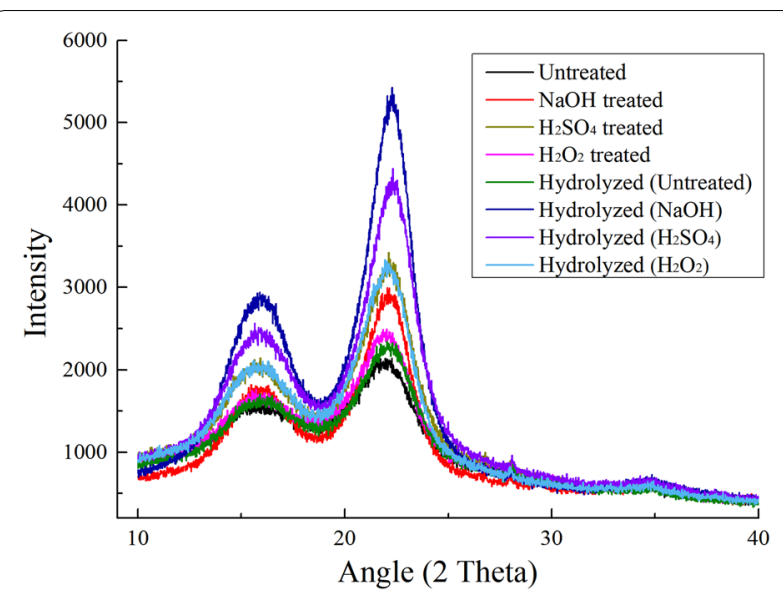

Fig. 2 XRD images of SSS after pretreatment and enzymatic hydrolysis

Table 2 Crystallinity indices of SSS undergoing pretreatment and enzymatic hydrolysis

\begin{tabular}{lll}
\hline Samples & \multicolumn{2}{l}{ Crystallinity index $(\mathrm{Crl})$} \\
\cline { 2 - 3 } & Pretreatment & $\begin{array}{l}\text { Enzymatic } \\
\text { hydrolysis }\end{array}$ \\
\hline Untreated & 45.50 & 53.90 \\
$2 \% \mathrm{NaOH}$ & 69.30 & 77.47 \\
$2 \% \mathrm{H}_{2} \mathrm{SO}_{4}$ & 66.45 & 71.68 \\
$10 \% \mathrm{H}_{2} \mathrm{O}_{2}$ & 53.06 & 64.95 \\
\hline
\end{tabular}

After hydrolysis, the highest CrI in alkali-pretreated SSS $(77.47 \%)$ indicated the high delignification capability of alkali pretreatment, thereby improving the enzymatic hydrolysis efficiency (Table 1 ).

\section{Scanning electron microscopy (SEM) analysis}

The surface morphology changes of SSS after pretreatment and enzymatic hydrolysis were investigated by using SEM. The untreated SSS showed a compact and rigid surface structure, and the only enzyme-hydrolyzed samples exhibited slight fiber splitting and surface abrasion (Fig. 3), which were consistent with our previous report described by Dong et al. [19]. The SEM image of $\mathrm{NaOH}$-pretreated SSS exhibited more loose porous structures and specific surface areas that could effectively increase the accessibility of cellulase to biomass, which were strongly supported by the increased fluorescence intensity of dyed cellulase after alkali pretreatment in CLSM (Fig. 5). These morphological changes were caused by the reaction of alkali which leads to the removal of the surface lignin layer and release of cell shape of cellulose from the biomass matrix [19]. After hydrolysis of $\mathrm{NaOH}$ pretreated SSS, much of the cell shape of cellulose was dissolved and more surface collapse was seen. The $2 \%$ $\mathrm{H}_{2} \mathrm{SO}_{4}$-pretreated samples showed a disorganized surface morphology characterized by the exposure of the loosely fibrous network. Ji et al. [48] investigated the structural changes in plant cell walls subjected to dilute acid pretreatment and found a sequence of pretreatment-induced
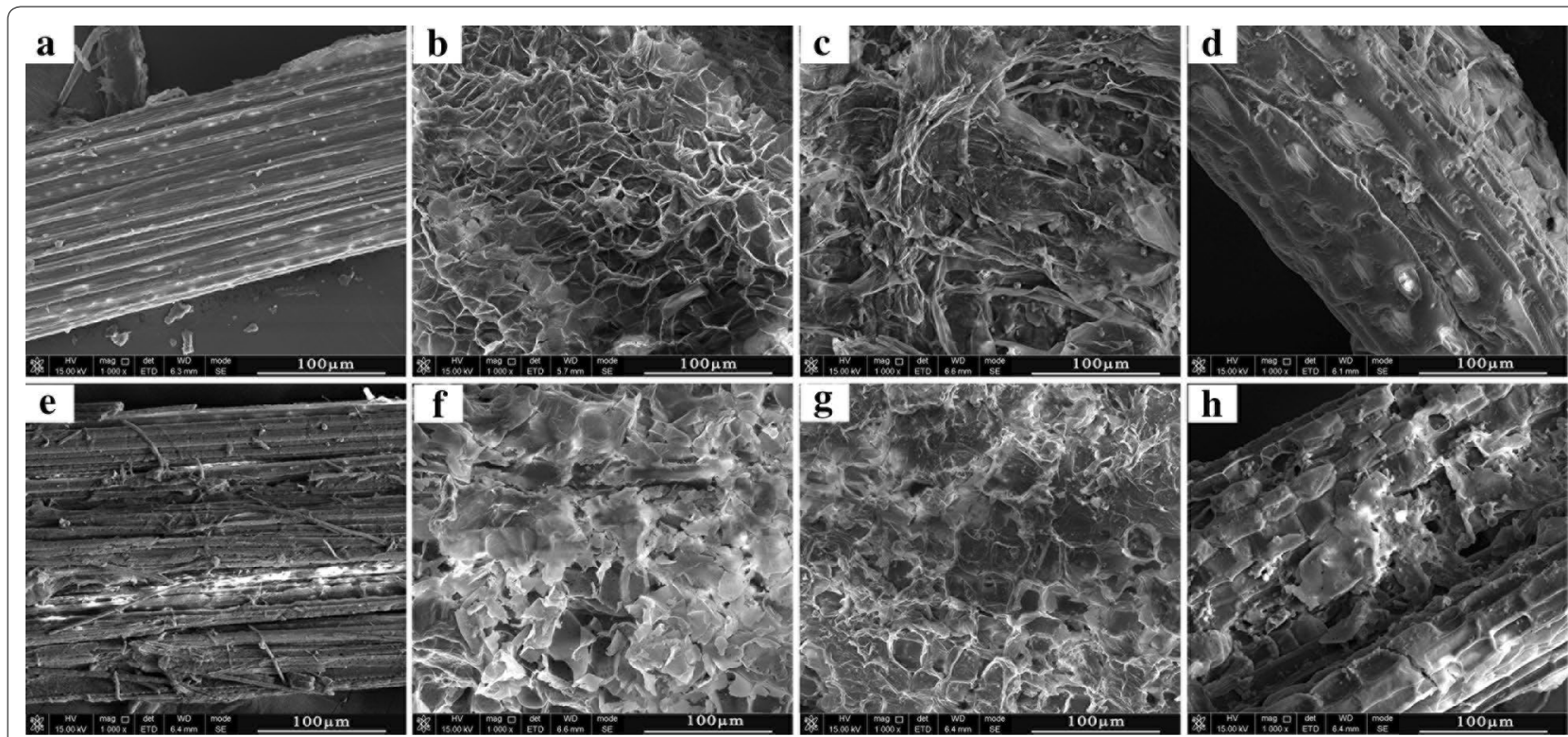

Fig. 3 SEM images ( $\times 1000$ magnification) of sweet sorghum straw. a Untreated. b-d $\mathrm{NaOH}, \mathrm{H}_{2} \mathrm{SO}_{4}$ and $\mathrm{H}_{2} \mathrm{O}_{2}$ pretreated, respectively. e Untreated and enzyme hydrolyzed. f- $\mathbf{h ~ N a O H}, \mathrm{H}_{2} \mathrm{SO}_{4}$ and $\mathrm{H}_{2} \mathrm{O}_{2}$ pretreated and enzyme hydrolyzed, respectively. Scale bars: $100 \mu \mathrm{m}$ 
deconstruction, including loss in the matrix between neighboring cell walls, removal of hemicelluloses and increased exposure of cellulose, thereby enhancing enzyme access to cellulose and further sugar yield. The image of hydrolyzed SSS after $\mathrm{H}_{2} \mathrm{SO}_{4}$ pretreatment showed slight surface collapse and hydrolysis of fibrous network, and the remaining structures could be lignin, minerals and other solid residues [49]. The $\mathrm{H}_{2} \mathrm{O}_{2}$ pretreatment caused the removal of surface wax and partial hemicellulose-lignin matrix, thus exhibiting a few internal fiber structures and some persistent solid residues still present after enzymatic hydrolysis.

\section{Visualization of enzymatic hydrolysis process of alkali-pretreated sweet sorghum straw}

Based on the delignification capability and hydrolysis efficiency for SSS, the alkali-pretreated SSS was used for further enzymatic hydrolysis process study.

\section{Real-time imaging on the enzymatic hydrolysis process of alkali-pretreated SSS}

Analyzing the enzymatic hydrolysis process of alkalipretreated SSS allows us to visualize the spatial variation of hydrolysis rate and deepen the understanding of the detailed digestion manner of cellulase to cell walls. Therefore, we chose to focus on the vascular bundle areas, as this section contains a number of cell types.
The transverse section of sweet sorghum stem showed the typical tissue structure of monocotyledons, including sclerenchyma cells (Sc) surrounding the vascular bundle (VB), parenchyma cells (Pc) and sieve tubes (St, Fig. 4a). Apparently, the hydrolysis rate in Pc far from VB was much faster than in Sc and VB, and the VB were degraded lastly (Additional file 1: Movie S1), indicating that the overall digestibility was negatively correlated with the residual lignin contents in pretreated cell walls. After $5 \mathrm{~h}$ of hydrolysis, the complete degradation of Pc was observed with the $9 \mathrm{IU} / \mathrm{g}$ substrate enzyme loading. In addition, we recorded the real-time digestion process in which the cellulase dissolved the cell walls in the same manner (Fig. 4 and Additional file 1: Movie S1). The enzymatic digestion firstly occurred from the middle of the cell walls and then toward the cell wall corners, which was also supported by the CLSM results (Fig. $5 \mathrm{c}$ ). To the best of our knowledge, this study was the first report of the real-time imaging analysis of the enzymatic hydrolysis process in alkali-pretreated SSS.

\section{Visualization of accessibility and digestibility of cellulase to alkali-pretreated cell walls during enzymatic hydrolysis} Although alkali pretreatment has been proved to be one of the most effective methods for biomass pretreatment, a detailed enzymatic hydrolysis process of cellulase to alkali-pretreated biomass is still lacking. Therefore, the
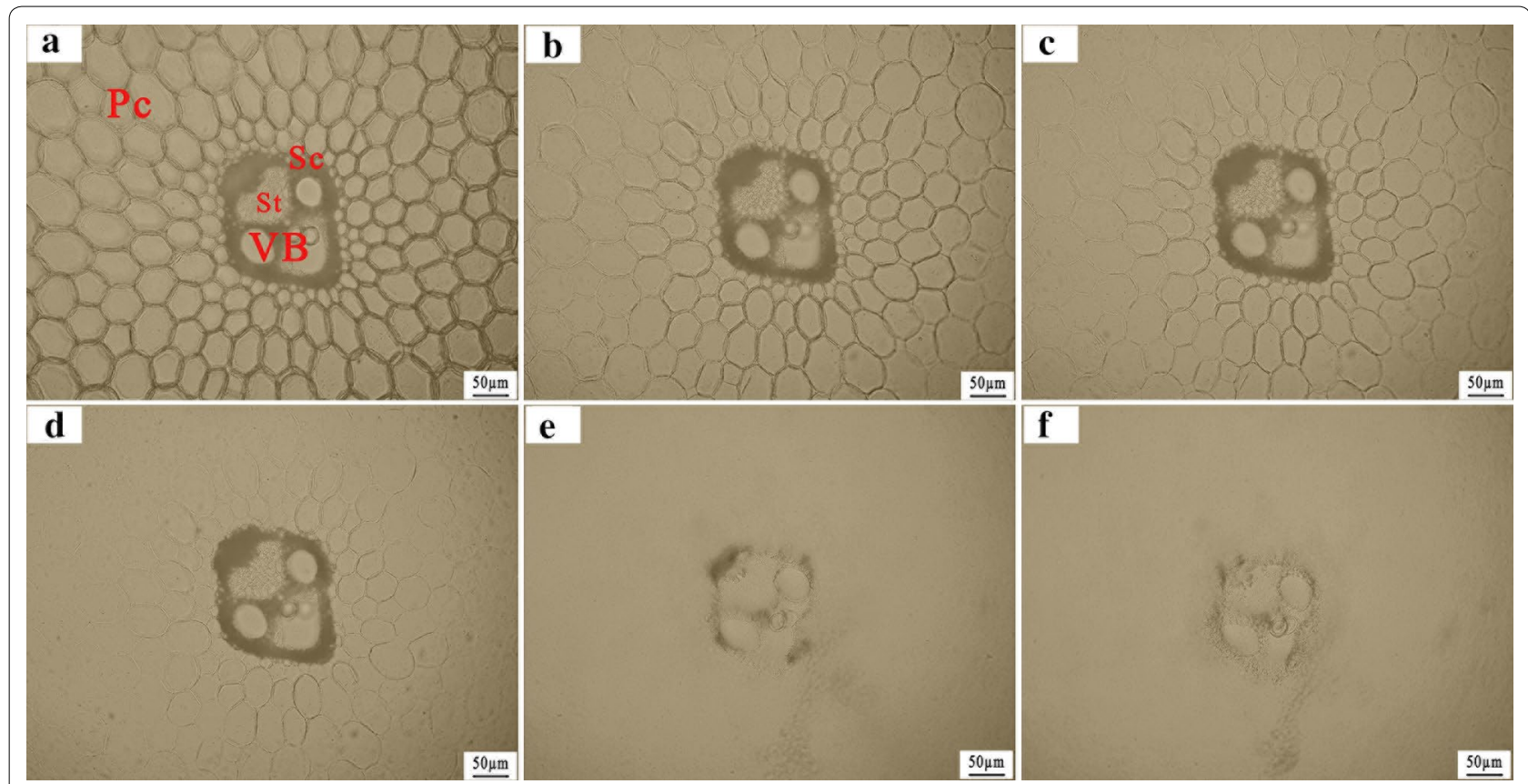

Fig. 4 Alkali-pretreated sweet sorghum straw (transverse section, $20 \mu \mathrm{m}$ in thickness) imaged in real time during enzymatic hydrolysis at room temperature (enzyme loading: $9 \mathrm{lU} / \mathrm{g}$ substrate). Image a-f were recorded with time intervals of 60 min using bright-field light microscopy. $P C$ parenchyma cells, VB vascular bundles, Sc sclerenchyma cells, St sieve tube. Scale bars: $50 \mu \mathrm{m}$ 

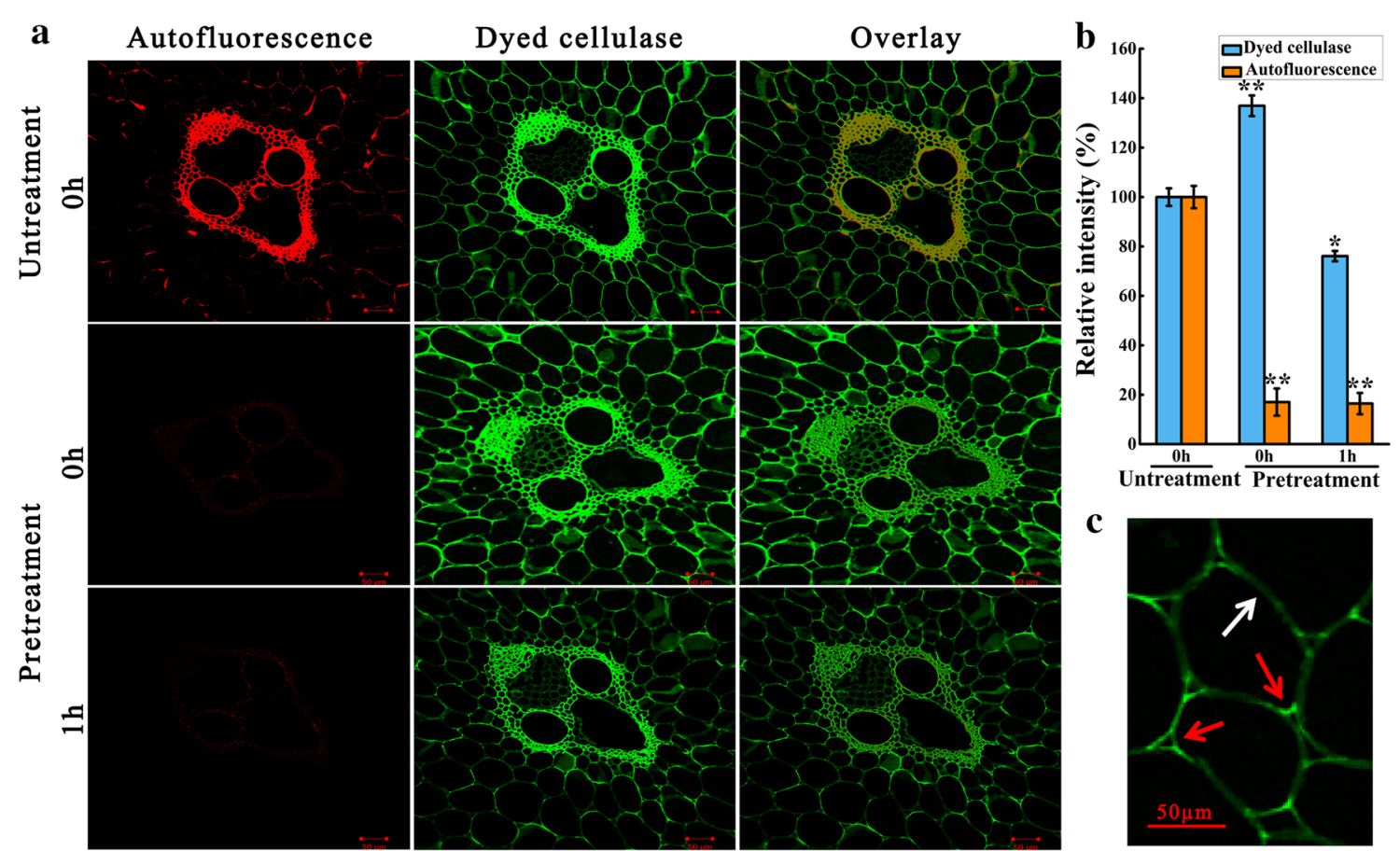

Fig. 5 CLSM images of transverse section (10 $\mu \mathrm{m}$ in thickness). a The autofluorescence and dye-labeled fluorescence of cell walls (vascular bundle area) with or without alkali pretreatment. $\mathbf{b}$ The relative fluorescence intensities of dye-labeled cellulase and autofluorescence of samples at the same conditions, which were expressed as percentages compared with the intensities of fluorescence in untreated samples that were designated as 100\%, respectively. c The changes in intensity of dye-labeled fluorescence between the corner (red arrows) and middle (white arrows) of alkali-pretreated parenchyma cell wall after hydrolysis of $1 \mathrm{~h}$. Scale bars: $50 \mu \mathrm{m}$

CLSM was used to visualize the spatial changes in the accessibility and digestibility of cellulase to pretreated biomass, and the changes in content of heterogeneous components during hydrolysis were also visualized.

The detailed distribution of lignin autofluorescence in untreated SSS are presented in Fig. 5a. The Sc, VB and corners of Pc in natural SSS were highly lignified, thereby exhibiting strong autofluorescence. Ji et al. [48] reported that the raw material of Miscanthus $\times$ giganteus had a heterogeneous distribution of lignin component, clearly exhibiting high intensity in the metaxylem vessel, followed by Sc and Pc. Similarly, Hou et al. [50] also reported that the lignin components prefer accumulating in Sc, compound middle lamella and corners of Pc in rice straw. These observations were in agreement with the general plant anatomy. However, the alkali pretreatment significantly decreased the autofluorescence intensity of SSS $(P<0.01$, Fig. 5a, b), indicating the occurrence of strong delignification. The extensive delignification in alkali-pretreated SSS was well supported by the disappearance of the bands at $1735 \mathrm{~cm}^{-1}$ and $1510 \mathrm{~cm}^{-1}$ in the FTIR spectra (Fig. 1a). In addition, the increased $\mathrm{CrI}$ in alkali-pretreated SSS also supported the occurrence of delignification, because the lignin was amorphous in the native biomass (Fig. 2). In particular, most of the lignin located in the corners of Pc was removed thoroughly, consistent with the fast hydrolysis of Pc observed in our study (Fig. 4). However, the autofluorescence intensity did not change significantly after $1 \mathrm{~h}$ of hydrolysis, indicating that the residual lignin in cell walls could not be degraded by cellulase (Fig. 5b).

Although the presence of lignin component was considered to be a significant restricting factor in enzymatic hydrolysis of biomass [51], the mechanism of lignin affects enzyme digestibility by a physical barrier on the cellulose surface or the nonproductive binding to enzyme remains open to debate. Ding et al. [14] reported that the cellulase binds strongly to nonlignified primary walls and more weakly to highly lignified sclerenchyma-type secondary walls. They demonstrated that the accessibility of untreated biomass to enzyme binding exhibited negative correlation with its lignin content, which could hinder the binding of cellulase to biomass. However, as can be seen from the untreated samples (Fig. 5a), the dyelabeled fluorescence was non-selectively distributed in the transverse sections of parenchyma cells and highly lignified vascular bundles, indicating the occurrence of nonproductive binding of cellulase to lignin. Similarly, 
the nonproductive binding of cellulase to lignin has been reported by previous studies $[48,52]$. Thus, we can conclude that the effect of lignin on enzyme digestibility was mainly attributed to the nonproductive bindings of cellulase to lignin, thereby increasing the recalcitrance of the biomass.

As anticipated, the fluorescence intensity of dyed cellulase in alkali-pretreated samples significantly increased at the initial stage of digestion $(0 \mathrm{~h})$, indicating that the alkali pretreatment increased the cellulase absorption ability on biomass. This increase of absorption ability in biomass to cellulase was mainly caused by the removal of lignin and partial hemicellulose, thereby increasing the porosity in biomass and providing more sites for cellulase binding to substrate [53], which were in good agreement with the structural characterization results of SEM in alkali-pretreated SSS (Fig. 3b). After $1 \mathrm{~h}$ of hydrolysis, the dye-labeled fluorescence intensity declined (Fig. 5b), which was attributed to the dissociation of dyed cellulase absorbed in cellulose due to the partial digestion of cellulose [54]. In addition, the fluorescence intensity of dyed cellulase in the middle of the cell walls was lower than in the cell wall corners (Fig. 5c), indicating that the middle of cell walls were firstly digested during the enzymatic hydrolysis, thereby causing the dissociation of cellulase from cellulose [15].

Therefore, based on the detailed digestion process of plant cell walls and the spatial variation of hydrolysis rate in various plant tissues, the future of research aimed at enhancing biomass hydrolysis efficiency will primarily focus on the genetic engineering design of plant cell structure (including the types of cells or ratios of primary and secondary cell walls) or plant tissues at the organization level. In future, for biorefineries to produce biofuels from biomass economically and effectively, these findings from pretreatment and enzymatic hydrolysis process could be integrated into the conversion processes, thereby enhancing the overall biomass processing efficiency.

\section{Conclusion}

Greater understanding of pretreatment and enzymatic hydrolysis of biomass is the key to lignocellulose processing. The structural characterization by XRD, FTIR and SEM and enzymatic hydrolysis indicated that the alkali pretreatment was the most effective method for delignification and enzymatic digestion among the dilute acid, alkali and hydrogen peroxide pretreatment of SSS. The visualization of the enzymatic hydrolysis process revealed that the cellulase dissolved the cell walls in a same manner and the overall digestibility was negatively correlated with the lignin contents of SSS. In addition, the efficient pretreatment significantly changed the spatial accessibility and digestibility of cellulase to lignocellulose, thereby improving the hydrolysis efficiency.

\section{Supplementary information}

Supplementary information accompanies this paper at https://doi. org/10.1186/s13068-019-1613-6.

Additional file 1: Movie S1. Bright-field light microscopy of hydrolysis of alkali-pretreated transverse section showing the vascular bundle area digestion by cellulase for $6 \mathrm{~h}$ at room temperature. $10 \times$ lens, $x / y=2980 / 2272$ pixel. The movie was played back at 1000 times actual hydrolysis speed.

\section{Abbreviations}

SSS: sweet sorghum straw; FTIR: Fourier transform infrared; XRD: X-ray diffractogram; SEM: scanning electron microscopy; CLSM: confocal laser scanning microscopy; FPU: filter paper activity; FITC: fluorescein isothiocyanate; DMSO: dimethyl sulfoxide; Crl: crystallinity index; Pc: parenchyma cells; VB: vascular bundles; Sc: sclerenchyma cells; St: sieve tube.

\section{Acknowledgements}

We thank the National Natural Science Foundation of China (No. 11305225), the key projects of the Chinese Academy of Sciences (KFZD-SW-109).

\section{Authors' contributions}

$\mathrm{MD}$ and SW conceived and designed the study and drafted the manuscript. FX, JW, and QL conducted part of enzymatic hydrolysis and structural characterization experiments of sweet sorghum straw. NY and JC interpreted experimental data and reviewed the manuscript. SW and WL supported the research funding. All authors read and approved the final manuscript.

\section{Funding}

This study is supported by the National Natural Science Foundation of China (No. 11305225), the key projects of the Chinese Academy of Sciences (KFZD-SW-109).

\section{Availability of data and materials}

All data generated or analyzed during this study are included in this published article and its Additional file.

\section{Ethics approval and consent to participate}

Not applicable.

\section{Consent for publication}

Not applicable.

\section{Competing interests}

The authors declare that they have no competing interests.

\section{Author details}

${ }^{1}$ Institute of Modern Physics, Chinese Academy of Sciences, 509 Nanchang Rd., Lanzhou 730000, Gansu, People's Republic of China. ${ }^{2}$ Institute of Biology, Gansu Academy of Sciences, 197 Dingxi South Rd., Lanzhou 730000, Gansu, People's Republic of China. ${ }^{3}$ College of Life Sciences, University of Chinese Academy of Sciences, No. 19A Yuquan Road, Beijing 100049, People's Republic of China. ${ }^{4}$ College of Physics and Electronic Engineering, Northwest Normal University, Anning Rd., Lanzhou 730000, Gansu, People's Republic of China. ${ }^{5}$ College of Life Sciences, Northwest Normal University, Anning Rd., Lanzhou 730000, Gansu, People's Republic of China.

Received: 2 September 2019 Accepted: 10 November 2019 Published online: 23 November 2019 


\section{References}

1. Ragauskas AJ, Williams CK, Davison BH, Britovsek G, Cairney J, Eckert CA, et al. The path forward for biofuels and biomaterials. Science. 2006;311:484-9

2. Jing Y, Guo Y, Xia Q, Liu X, Wang Y. Catalytic production of value-added chemicals and liquid fuels from lignocellulosic biomass. Chem. 2019. https://doi.org/10.1016/j.chempr.2019.05.022.

3. Zhang Z, Song J, Han B. Catalytic transformation of lignocellulose into chemicals and fuel products in ionic liquids. Chem Rev. 2017;117:6834-80.

4. Zhou CH, Xia X, Lin CX, Tong DS, Beltramini J. Catalytic conversion of lignocellulosic biomass to fine chemicals and fuels. Chem Soc Rev. 2011:40:5588-617.

5. Fu HM, Chen YH, Yang XM, Di JY, Xu MG, Zhang BG. Water resource potential for large-scale sweet sorghum production as bioenergy feedstock in Northern China. Sci Total Environ. 2019;653:758-64.

6. Artzi L, Bayer EA, Morais S. Cellulosomes: bacterial nanomachines for dismantling plant polysaccharides. Nat Rev Microbiol. 2017;15:83.

7. Brodeur G, Yau E, Badal K, Collier J, Ramachandran KB, Ramakrishnan S. Chemical and physicochemical pretreatment of lignocellulosic biomass: a review. Enzyme Res. 2011;2011:1-17.

8. Himmel ME. Biomass recalcitrance: engineering plants and enzymes for biofuels production. Science. 2007;316:982.

9. Xu F, Wang J, Dong M, Wang S, Xiao G, Li Q, et al. Enhancing enzymatic hydrolysis yield of sweet sorghum straw polysaccharides by heavy ion beams irradiation pretreatment. Carbohydr Polym. 2019;222:114976.

10. Bhutto AW, Qureshi K, Harijan K, Abro R, Abbas T, Bazmi AA, et al. Insight into progress in pre-treatment of lignocellulosic biomass. Energy. 2017:122:724-45.

11. Chaturvedi V, Verma P. An overview of key pretreatment processes employed for bioconversion of lignocellulosic biomass into biofuels and value added products. 3 Biotech. 2013;3:415e31.

12. Kim JS, Lee YY, Kim TH. A review on alkaline pretreatment technology for bioconversion of lignocellulosic biomass. Bioresour Technol. 2016;199:42-8.

13. Horikawa Y, Imai T, Sugiyama J. Visualization of cellulase interactions with cellulose microfibril by transmission electron microscopy. Cellulose. 2017:24:1-9.

14. Ding SY, Liu YS, Zeng YN, Himmel ME, Baker JO, Bayer EA. How does plant cell wall nanoscale architecture correlate with enzymatic digestibility. Science. 2012;338:1055-60.

15. He P, Chai L, Li L, Hao L, Shao L, Lü F. In situ visualization of the change in lignocellulose biodegradability during extended anaerobic bacterial degradation. RSC Adv. 2013;3:11759.

16. Nakamura A, lino R. Visualization of functional structure and kinetic dynamics of cellulases. Glycobiophysics. 2018;1104:201-17.

17. Schmidt M, Schwartzberg AM, Perera PN, Weber-Bargioni A, Carroll A, Sarkar P, et al. Label-free in situ imaging of lignification in the cell wall of low lignin transgenic Populus trichocarpa. Planta. 2009;230:589-97.

18. Kim MY, Jung AR, Kim GE, Yang J, Ha US, Hong SH, et al. High FOXM1 expression is a prognostic marker for poor clinical outcomes in prostate cancer. J Cancer. 2019;10:749-56.

19. Dong MY, Wang SY, Xiao GQ, Xu FQ, Hu W, Li QQ, et al. Cellulase production by Aspergillus fumigatus MS13.1 mutant generated by heavy ion mutagenesis and its efficient saccharification of pretreated sweet sorghum straw. Process Biochem. 2019;84:22-9.

20. Yan ZP, Li JH, Li SZ, Chang S, Cui T, Jiang Y, et al. Impact of lignin removal on the enzymatic hydrolysis of fermented sweet sorghum bagasse. Appl Energy. 2015;160:641-7

21. Sluiter A, Hames B, Ruiz R, et al. Determination of structural carbohydrates and lignin in biomass, NREL/TP-510-42618[R]. Denver: National Renewable Energy Lab; 2008.

22. de Oliveira Rodrigues P, dos Santos BV, Costa L, Henrique MA, Pasquini D, Baffi MA. Xylanase and $\beta$-glucosidase production by Aspergillus fumigatus using commercial and lignocellulosic substrates submitted to chemical pre-treatments. Ind Crops Prod. 2017:95:453-9.

23. Segal L, Creely JJ, Martin AE, Conrad CM. An empirical method for estimating the degree of crystallinity of native cellulose using the $X$-ray diffractometer. Text Res J. 1959;29:786-94.

24. Kapoor M, Raj T, Vijayaraj M, Chopra A, Gupta RP, Tuli DK, et al. Structural features of dilute acid, steam exploded, and alkali pretreated mustard stalk and their impact on enzymatic hydrolysis. Carbohydr Polym 2015;124:265-73.

25. Dipam P, Baruah DC. Effect of combined chemical and thermal pretreatments on biogas production from lignocellulosic biomasses. Ind Crops Prod. 2018:124:735-46.

26. Khalid MJ, Waqas A, Nawaz I. Synergistic effect of alkaline pretreatment and magnetite nanoparticle application on biogas production from rice straw. Bioresour Technol. 2019;275:288-96.

27. Tsegaye B, Balomajumder C, Roy P. Alkali pretreatment of wheat straw followed by microbial hydrolysis for bioethanol production. Environ Technol. 2017:40:1-28.

28. Moxley G, Gaspar AR, Higgins D, Xu H. Structural changes of corn stover lignin during acid pretreatment. J Ind Microbiol Biotechnol. 2012;39:1289-99.

29. loelovich M, Morag E. Study of enzymatic hydrolysis of mild pretreated lignocellulosic biomasses. BioResources. 2012;7:1040-52.

30. Kim SB, Um BH, Park SC. Effect of pretreatment of reagent and hydrogen peroxide on enzymatic hydrolysis of oak in percolation process. Appl Biochem Biotechnol. 2001;91:81-94.

31. Li Y, Cui J, Zhang G, Liu Z, Guan H, Hwang H, Wang P. Optimization study on the hydrogen peroxide pretreatment and production of bioethanol from seaweed Ulva prolifera biomass. Bioresour Technol. 2016;214:144-9.

32. Wu H, Dai X, Zhou SL, Gan YY, Xiong ZY, Qin YH. Ultrasound-assisted alkaline pretreatment for enhancing the enzymatic hydrolysis of rice straw by using the heat energy dissipated from ultrasonication. Bioresour Technol. 2017;241:70-4.

33. Olsson AM, Salmén L. The association of water to cellulose and hemicellulose in paper examined by FTIR spectroscopy. Carbohydr Res. 2004;339:813-8.

34. Kalutskaya EP, Gusev SS. An infrared spectroscopic investigation of the hydration of cellulose. Polym Sci USSR. 1980;22:550-6.

35. Liang CY, Marchessault RH. Infrared spectra of crystalline polysaccharides. I. Hydrogen bonds in native celluloses. J Polym Sci. 1959;37:385-95.

36. McMillan JD. Pretreatment of lignocellulosic biomass. In: Himmel ME, Baker JO, Overend RP, et al. editors. Enzymatic conversion of biomass for fuels production. Proceeding of the 205th national meeting of the American Chemical Society; 1994. p. 292-324.

37. Zhao X, Zhang L, Liu D. Biomass recalcitrance. Part I: the chemical compositions and physical structures affecting the enzymatic hydrolysis of lignocellulose. Biofuels Bioprod Biorefin. 2012;6:465-82.

38. Pan X, Gilkes N, Saddler JN. Effect of acetyl groups on enzymatic hydrolysis of cellulosic substrates. Holzforschung. 2006;60:398-401.

39. Meng X, Ragauskas AJ. Recent advances in understanding the role of cellulose accessibility in enzymatic hydrolysis of lignocellulosic substrates. Curr Opin Biotechnol. 2014;27:150-8.

40. Bura R, Chandra R, Saddler J. Influence of xylan on the enzymatic hydrolysis of steam-pretreated corn stover and hybrid poplar. Biotechnol Prog. 2009;25:315-22.

41. Zhu JY. Physical pretreatment-woody biomass size reduction-for forest biorefinery. Sustainable production of fuels, chemicals, and fibers from forest biomass., ACS Symposium SeriesWashington, DC: American Chemical Society; 2011. p. 89-107.

42. Nelson ML, O'Connor RT. Relation of certain infrared bands to cellulose crystallinity and crystal lattice type. Part II. A new infrared ratio for estimation of crystallinity in celluloses I and II. J Appl Polym Sci. 1964;8:1325-41.

43. Liu Z, Sun X, Hao M, Huang C, Xue Z, Mu T. Preparation and characterization of regenerated cellulose from ionic liquid using different methods. Carbohydr Polym. 2015;117:99-105.

44. Kuo CH, Lee CK. Enhancement of enzymatic saccharification of cellulose by cellulose dissolution pretreatments. Carbohydr Polym. 2009;77:41-6.

45. Rajput AA, Visvanathan C. Effect of thermal pretreatment on chemical composition, physical structure and biogas production kinetics of wheat straw. J Environ Manag. 2018;221:45-52.

46. Kainthola J, Kalamdhad AS, Goud VV, Goel R. Fungal pretreatment and associated kinetics of rice straw hydrolysis to accelerate methane yield from anaerobic digestion. Bioresour Technol. 2019;286:121368.

47. Zhang YHP, Lynd LR. Toward an aggregated understanding of enzymatic hydrolysis of cellulose: noncomplexed cellulase systems. Biotechnol Bioeng. 2004;88:797-824.

48. Ji Z, Zhang X, Ling Z, Zhou X, Ramaswamy S, Xu F. Visualization of Miscanthus $\times$ giganteus cell wall deconstruction subjected to dilute acid 
pretreatment for enhanced enzymatic digestibility. Biotechnol Biofuels. 2015;8:103.

49. Auxenfans T, Crônier D, Chabbert B, Paës G. Understanding the structural and chemical changes of plant biomass following steam explosion pretreatment. Biotechnol Biofuels. 2017;10:36.

50. Hou XD, Li N, Zong MH. Renewable bio ionic liquids-water mixturesmediated selective removal of lignin from rice straw: visualization of changes in composition and cell wall structure. Biotechnol Bioeng. 2013:110:1895-902.

51. Vanholme R, Demedts B, Morreel K, Ralph J, Boerjan W. Lignin biosynthesis and structure. Plant Physiol. 2010;153:895-905.

52. Ooshima H, Burns DS, Converse AO. Adsorption of cellulase from Trichoderma reesei on cellulose and lignacious residue in wood pretreated by dilute sulfuric acid with explosive decompression. Biotechnol Bioeng. 1990;36:446-52.
53. Oyarce P, De Meester B, Fonseca F, de Vries L, Goeminne G, Pallidis A, Sels B. Introducing curcumin biosynthesis in Arabidopsis enhances lignocellulosic biomass processing. Nat Plants. 2019;5:225.

54. Nakamura A, Watanabe H, Ishida T, Uchihashi T, Wada M, Ando T, et al. Trade-off between processivity and hydrolytic velocity of cellobiohydrolases at the surface of crystalline cellulose. J Am Chem Soc. 2014;136:4584-92.

\section{Publisher's Note}

Springer Nature remains neutral with regard to jurisdictional claims in published maps and institutional affiliations.
Ready to submit your research? Choose BMC and benefit from:

- fast, convenient online submission

- thorough peer review by experienced researchers in your field

- rapid publication on acceptance

- support for research data, including large and complex data types

- gold Open Access which fosters wider collaboration and increased citations

- maximum visibility for your research: over $100 \mathrm{M}$ website views per year

At BMC, research is always in progress.

Learn more biomedcentral.com/submissions 